\title{
Treino sem Conseqüências Diferenciais: Importância Conceitual, Metodológica e Algumas Implicações Educacionais ${ }^{1}$
}

\author{
Marcelo Quintino Galvão Baptista² e Grauben José Alves de Assis \\ Universidade Federal do Pará
}

\begin{abstract}
RESUMO: Neste trabalho, retomamos os principais estudos sobre o treino de discriminações condicionais sem conseqüências diferenciais implementados em nosso laboratório com humanos desprovidos de história prévia de participação como sujeitos. Buscamos descrever os procedimentos utilizados e discutimos os resultados em torno de aspectos conceituais e metodológicos a respeito dos quais os estudos podem ser inter-relacionados - a questão do reforço (a temporalidade com que este segue o desempenho, enquanto uma característica envolvida em sua definição) e fontes alternativas de controle (o pareamento Modelo-Sc e Modelo-Si, bem como a reexposição às tentativas de treino). Finalmente, relacionamos o procedimento geral dos estudos com a postura do professor em sala de aula e sugerimos algumas implicações educacionais dele decorrentes, como podendo estar envolvidas na programação e implementação do ensino.
\end{abstract}

Palavras-chave: treino por consistência de estímulos; conseqüências diferenciais; fontes alternativas de controle; ensino.

\section{Training Without Differential Consequences: Conceptual and Methodological Importance, and Some Educational Implications}

\begin{abstract}
In this article we review the principal findings from a series of studies about conditional discrimination training without differential consequences, which have been conducted in our laboratory with human participants who had no previous experience as research subjects. We seek to describe the procedures utilized and discuss the results obtained with reference to conceptual and methodological aspects which these studies share in common. In particular, we focus on reinforcement (in terms of its temporal schedule), and alternative sources of control (Sample-Sc and Sample-Si matching, as well as reexposure to the training trials). Finally, we draw a relationship between the procedural routine and the role of teachers in the classroom, and suggest some educational implications which may be involved in the programming and implementation of instructional strategies.
\end{abstract}

Key words: consistency training; differential consequences; alternative controls; teaching.

No ensino de discriminações condicionais, tem sido tradicionalmente usado o procedimento de matching-tosample (ou pareamento de acordo com o modelo), com reforçamento explícito ou conseqüências diferenciais (Sidman \& Tailby, 1982; Sidman, 1992, Sidman, 1994). Tipicamente, nesse procedimento, a resposta ao estímulo modelo produz o aparecimento de dois ou mais estímulos de comparação; a resposta ao estímulo de comparação considerado correto é reforçada e a escolha do estímulo incorreto produz uma conseqüência aversiva. O estímulo de comparação correto é aquele que compartilha de algum tipo de relação com o modelo. Com esse procedimento, tem sido amplamente documentada a formação de classes de estímulos indicativas de discriminações ou relações condicionais entre os membros, decorrentes do treino direto ou reforçamento explícito. Submetidas a testes específicas, essas relações têmse mostrado também equivalentes, exibindo as propriedades

1 Os autores agradecem ao Prof. Dr. Júlio César C. de Rose pelo desafio e incentivo à elaboração deste trabalho, principalmente no que respeita a implicações educacionais derivadas dos estudos sobre pareamento consistente que ele vem acompanhando.

2 Endereço: Avenida Conselheiro Furtado, 1698, apto. 304, Cremação, Belém, Pará - 66.100-040. E-mail: mgalvao@amazon.com.br. que as caracterizam como tais - a reflexividade, a simetria e a transitividade.

Estudos recentes, voltados a discriminações condicionais através de treino envolvendo pareamento consistente de estímulos sem reforçamento explícito ou conseqüências diferenciais imediatas, em cada tentativa, inauguraram, entretanto, a possibilidade de introdução de alguns aspectos metodológicos que permitem serem tratados como alternativos aos tradicionais. Definimos como um exemplo de pareamento consistente de estímulos o procedimento de um estudo pioneiro (Baptista \& Assis, 1995), no qual não houve conseqüências diferenciais imediatas em cada tentativa de treino. No estudo, o que caracterizou esse treino, foi o fato de o estímulo consistente $(S c)$ ser apresentado em todas as tentativas de um bloco, em conjunto com um modelo e pelo menos dois estímulos inconsistentes variando a cada duas tentativas consecutivas ao longo de cada bloco. Em cada tentativa de um mesmo bloco, a resposta a quaisquer estímulos, quer o consistente quer o inconsistente, produzia sempre uma nova configuração dos mesmos na tela, sendo, portanto, essa nova configuração, a única conseqüência para as respostas, uma conseqüência não diferencial. Assim, esse tipo de pareamento tornou muito provável a escolha do estímulo consistente, 
dada a alta freqüência com que foi apresentado, em detrimento da escolha de quaisquer estímulos inconsistentes, apresentados com uma baixa freqüência.

Os dois primeiros estudos que nos propiciaram identificar o treino por consistência de estímulos (embora os autores não o tenham explicitamente assim), foram realizados por Saunders, Saunders, Kirby e Spradlin (1988) e Harrison e Green (1990, Experimento 2). Estudos posteriores (Baptista \& Assis, 1995; Álvares, 1996; Assis, Baptista, Damin \& Álvares, 1997; Barros, Baptista \& Assis, 1998; Damin, Assis \& Baptista, 1998) replicaram os primeiros, enquanto um refinamento de procedimento. Comum nesses estudos, que denominamos de alternativos, foi o arranjo de treino, ou seja, a forma como as tentativas foram estruturadas, de modo a reduzir as possibilidades de controle por outras fontes (Sidman, 1992).

Com o presente trabalho, objetivamos descrever esses estudos (alternativos), assinalando alguns aspectos do procedimento geral e básico usado em cada um. Buscamos mostrar, também, algumas relações entre os estudos e discutir a sua importância em termos teóricos e metodológicos. E, finalmente, discutir a importância do procedimento de treino por consistência de estímulos e dos resultados produzidos, para a derivação de possíveis implicações educacionais, nomeadamente as envolvidas em situações específicas de programação de ensino, nas quais nem sempre é possível que o professor libere conseqüências diferenciais para o desempenho acadêmico de seus alunos.

\section{Caracterização dos Estudos}

\section{Procedimento geral}

Situação Experimental e Equipamento. As sessões foram conduzidas em uma sala do nosso laboratório. Havia na sala, uma mesa com um microcomputador (IBM-PC 300 Mhz) contendo um monitor SVGA de tela sensível ao toque, através do qual os estímulos eram apresentados; duas cadeiras, uma posicionada de frente para o computador e outra posicionada ao lado da primeira e, ainda, uma filmadora localizada atrás do participante. A reposta deste consistia em tocar levemente com os dedos as "janelas" (na tela sensível) que mediam 4 x 4cm. Programas foram desenvolvidos em linguagens específicas, para o controle do experimento. As entrevistas pós-experimentais foram transcritas posteriormente.

Estímulos. Os estímulos foram figuras geométricas usuais e formas abstratas (ver Quadro 1). O Quadro 1 apresenta um sumário da caracterização dos estudos, por tipo, idade e sexo dos participantes, tipo de estímulos e procedimento.

Quadro 1. Caracterização dos Estudos 1, 2, 3 e 4 (Baptista \& Assis, 1995; Assis, Baptista, Damin \& Alvares, 1997; Damin, Assis \& Baptista, 1998; Barros, Baptista \& Assis, 1998), por tipo, idade e sexo dos participantes, tipo de estímulos e procedimento utilizado.

\begin{tabular}{|c|c|c|c|c|c|}
\hline \multirow{2}{*}{ Estudo } & \multicolumn{3}{|c|}{ Participantes } & \multirow{2}{*}{ Estímulos } & \multirow{2}{*}{ Procedimento } \\
\hline & Tipo & Idade & Sexo & & \\
\hline 1. $\quad$ Baptista \& Assis (1995) & 4 universitários & $19-33 a$ & $\begin{array}{l}1 \mathrm{M} \\
3 \mathrm{~F}\end{array}$ & $\begin{array}{l}\text { Figuras usuais (facilmente } \\
\text { discrimináveis) }\end{array}$ & $\begin{array}{l}\text { - Pareamento consistente com o modelo envolvendo } 3 \text { escolhas sem } \\
\text { conseqüências diferenciais. } \\
\text { - Treino AB, AC, AD e Testes de Simetria BA, CA, DA e de } \\
\text { Equivalência BC, CB, BD, DB, CD, DC. Os testes foram } \\
\text { aplicados com atraso, isto é, após a revisão da linha de base. } \\
\text { - Um estímulo de comparação consistente (Sc) em todas as tentativas e } \\
\text { dois outros inconsistentes ( } \mathrm{Si} \text { ) (variando a cada duas tentativas } \\
\text { consecutivas. } \\
\text { - Blocos de } 36 \text { tentativas no treino e nos testes. }\end{array}$ \\
\hline $\begin{array}{ll}\text { 2. } & \text { Assis, Baptista, Damin \& } \\
& \text { Alvares (1997) }\end{array}$ & 4 universitários & $18-23 a$ & $\begin{array}{l}2 \mathrm{M} \\
5 \mathrm{~F}\end{array}$ & Idem (Estudo 1) & $\begin{array}{l}\text { - Pareamento consistente com o modelo envolvendo } 3 \text { escolhas sem } \\
\text { conseqüências diferenciais. } \\
\text { - } \text { Treino AB, AC, AD e Testes de Simetria BA, CA, DA e de } \\
\text { Equivalência BC, CB, BD, DB, CD, DC. } \\
\text { - } \text { Fading do modelo e do estímulo de comparação consistente para os } \\
\text { sujeitos CRL, RNT, DRI e MGI. } \\
\text { - } \quad \text { Não fading para os sujeitos MCA, TAB e JSC. } \\
\text { - Blocos de } 36 \text { tentativas no treino e nos testes. }\end{array}$ \\
\hline $\begin{array}{l}\text { 3. Damin, Assis \& Baptista } \\
\text { (1998) }\end{array}$ & 4 universitários & $18-23 a$ & $\begin{array}{l}3 \mathrm{M} \\
1 \mathrm{~F}\end{array}$ & Idem (Estudo 1) & $\begin{array}{l}\text { - Pareamento consistente com o modelo envolvendo } 3 \text { escolhas sem } \\
\text { conseqüências diferenciais. } \\
\text { - Treino } \mathrm{AB}, \mathrm{AC}, \mathrm{AD} \text {. Cada relação específica em cada treino } \\
\text { condicional (por exemplo, A1B1, A2B2, A3B3 era seguida } \\
\text { imediatamente do teste da relação inversa (por exemplo, B1A1) e da } \\
\text { Simteria correspondente. Após isso, eram testadas as relações de } \\
\text { Equivalência } \mathrm{BC} / \mathrm{CB} ; \mathrm{BD} / \mathrm{DB} \text { e } \mathrm{DC} / \mathrm{CD} \text { com a revisão prévia dos } \\
\text { treinos mistos correspondentes }(\mathrm{AB} / \mathrm{AC} ; \mathrm{AB} / \mathrm{AD} \text { e } \mathrm{AC} / \mathrm{AD}) \text {. } \\
\text { - Blocos de } 36 \text { tentativas no treino e nos testes. }\end{array}$ \\
\hline $\begin{array}{l}\text { 4. } \begin{array}{l}\text { Barros, Baptista \& Assis } \\
\text { (1998) }\end{array}\end{array}$ & 4 universitários & $18-24 a$ & $1 \mathrm{M} 3 \mathrm{~F}$ & $\begin{array}{l}\text { Condição 1: } \\
\text { Idem (Estudo 1) } \\
\text { Condição 2: } \\
\text { Figuras não usuais ou } \\
\text { estranhas. }\end{array}$ & $\begin{array}{l}\text { - Pareamento consistente com o modelo envolvendo } 3 \text { escolhas sem } \\
\text { conseqüências diferenciais. } \\
\text { - Treino AB, AC, AD e Testes de Simetria BA, CA, DA e de } \\
\text { Equivalência BC, CB, BD, DB, CD, DC. } \\
\text { - Um estímulo de comparação consistente em todas as tentativas e dois } \\
\text { outros inconsistentes variando a cada duas tentativas consecutivas. } \\
\text { - Blocos de } 36 \text { tentativas no treino e nos testes. }\end{array}$ \\
\hline
\end{tabular}


Participaram nesses estudos, com exceção do Estudo 7, universitários sem história experimental prévia, de ambos os sexos, com idade variando entre 17 e 33 anos. No Estudo 7, os participantes eram crianças de 4 a 6 anos. Em todos os estudos, os estímulos foram figuras usuais, exceto na Condição 2 do Estudo 4 e no Experimento 2 do Estudo 7 nos quais foram usadas formas abstratas.

Delineamento Experimental. Houve as fases de Pré-Treino, Treino e Testes. No Estudo 5, além dos testes de Equivalência, houve testes de Seqüência (ver Quadro 1). Nos estudos, exceto no sétimo, o delineamento de treino e de testes foi longo. $\mathrm{O}$ treino envolveu as relações $\mathrm{AB}, \mathrm{AC}$ e $\mathrm{AD}$, nos Estudos 1, 2, 3, 4 e 6, e as relações AB, CD e EF, no Estudo 5. No Estudo 7, as relações treinadas forma $A B$ e AC. Os testes foram apresentados com atraso apenas no Estudo 1, isto é, após a revisão da linha de base.

O Pré-Treino era constituído de um bloco de 18 tentativas. Cada tentativa resumia-se na apresentação do modelo, na "janela" central do monitor, pareado, após uma resposta de observação, com estímulos de comparação que ocupavam as "janelas" laterais. Uma tentativa terminava quando uma resposta de escolha (tocar a tela com o dedo), em uma das "janelas" laterais, era emitida. Após um intervalo entre tentativas, de 1 segundo, uma nova configuração de estímulos era apresentada, independentemente do desempenho. $\mathrm{O}$ objetivo foi familiarizar cada participante com a situação experimental e com o procedimento, através de instruções mínimas na tela do monitor. No início de cada tentativa des- sa etapa, o modelo era apresentado isoladamente na "janela" central, acompanhado da Instrução 1: "Toque levemente a figura com o dedo". O experimentador lia a instrução e perguntava ao participante se a tinha compreendido. Caso negativo, a instrução era repetida e era feita uma demonstração pelo experimentador. Uma resposta de observação ao modelo produzia três novos estímulos de comparação posicionados nas "janelas" laterais, com a Instrução 2: " $T o-$ que levemente uma das figuras iluminadas". Foram utilizadas três das quatro "janelas" laterais, permanecendo uma vazia (desativada), a qual ficava na tela em diferentes posições. Quaisquer respostas adicionais ao modelo (quando sozinho) ou à "janela" desativada não produzia mudança na configuração dos estímulos e nenhuma outra conseqüência.

Os estímulos foram randomicamente alternados de posição nas quatros "janelas" laterais. Quando o participante respondia, as figuras e a instrução desapareciam durante 1 segundo para então reiniciar-se uma nova tentativa, e outro modelo era apresentado simultaneamente com a Instrução 1. Essa Fase terminava após 16 tentativas terem sido completadas.

No Treino (sem instruções), o procedimento era idêntico ao da fase anterior. O pareamento consistente foi caracterizado como descreveremos: juntamente a cada modelo era apresentado um $S c$, em todas as tentativas de cada bloco, e dois $\mathrm{Si}(\mathrm{s})$ que variavam a cada duas tentativas consecutivas; ou seja, o pareamento foi organizado de modo que nunca o mesmo $\mathrm{Si}$ era repetido por mais de duas tentativas seguidas

Quadro 1. (Continuação) - Caracterização dos Estudos 5, 6 e 7 (Lima, Assis, Baptista \& Sampaio, 1999; Assis, Baptista, Kato \& Alves, 2000 , Álvares, Assis, Esteves \& Sampaio (2001): por tipo, idade e sexo dos participantes, tipo de estímulos e procedimento utilizado.

\begin{tabular}{|c|c|c|c|c|}
\hline \multirow{2}{*}{ Estudo } & \multicolumn{3}{|c|}{ Participantes } & \multirow{2}{*}{ Estímulos } \\
\hline & Tipo & Idade & Sexo & \\
\hline $\begin{array}{l}\text { 5. Lima, Assis, Baptista \& } \\
\text { Sampaio (1999) }\end{array}$ & 5 universitários & $18-22 \mathrm{a}$ & $\begin{array}{l}2 \mathrm{M} \\
3 \mathrm{~F}\end{array}$ & $\begin{array}{l}\text { Idem (Estudo 1) e formas } \\
\text { geométricas abstratas }\end{array}$ \\
\hline
\end{tabular}

Pareamento consistente com o modelo envolvendo 3 escolhas sem
conseqüências diferenciais.

- Treino AB, CD, EF e Testes de Simetria BA, DC, FE

- Um estímulo modelo (dígito) foi pareado com fading com um estímulo de comparação (forma geométrica abstrata) consistente em todas as tentativas e dois outros inconsistentes variando a cada duas tentativas consecutivas.

Blocos de 36 tentativas no treino e 12 nos testes.

Testes de seqüenciação com as formas geométricas.

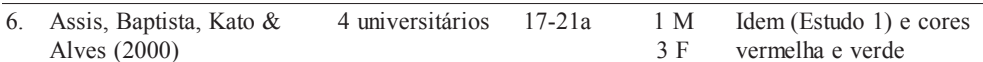

Pareamento consistente com o modelo envolvendo 3 escolhas sem conseqüências diferenciais.

- Treino AB, AC, AD e Testes de Simetria BA, CA, DA e de Equivalência BC, CB, BD, DB, CD, DC. Treino AD e teste de simetria DA sob controle contextual. Foram aplicados ainda testes de equivalência DB e DC sob controle contextual.

- Um estímulo de comparação consistente em todas as tentativas e dois outros inconsistentes variando a cada duas tentativas consecutivas.

Blocos de 36 tentativas no treino e nos testes.

7. Álvares, Assis, Esteves \& 11 crianças $\quad$ 04-06 6-M 5-F Figuras usuais (facilmente - Pareamento consistente com o modelo envolvendo 3 escolhas sem Sampaio (2001)

discrimináveis) no Experimento 1. Idem e formas geométricas abstratas no Experimento 2 conseqüências diferenciais.

- Treino $\mathrm{AB}$ e AC. Cada relação específica em cada treino condicional (por exemplo, A1B1, A2B2, A3B3 era seguida imediatamente do teste da relação inversa (por exemplo, B1A1) e da Simetria correspondente. Após isso, eram testadas as relações de Equivalência $\mathrm{BC} / \mathrm{CB}$, com a revisão prévia dos treinos mistos correspondentes $(\mathrm{AB} / \mathrm{AC})$.

- Um estímulo modelo e um estímulo de comparação consistente em fading (no Experimento 2) em todas as tentativas e dois outros inconsistentes variando a cada duas tentativas consecutivas.

Blocos de 24 tentativas no treino e nos testes. 
(ver uma amostra no Quadro 2). A escolha do $S c$, ou de quaisquer $\mathrm{Si}(\mathrm{s})$, produzia, como única conseqüência, uma nova configuração dos estímulos - o modelo apresentado sozinho, num primeiro momento; e num segundo momento, após a resposta ao modelo, o mesmo apresentado com esse $S c$ e dois $S i(\mathrm{~s})$, com a variação referida. A configuração era diferente da descrita, quando o participante era submetido ao treino misto (linha de base) em que os tipos de tentativas mudavam. Cada treino (por exemplo, $\mathrm{AB}$ misto) era constituído de um bloco de 36 tentativas, a partir da mistura de tentativas de um mesmo tipo de cada bloco de treino isolado (A1B1, A2B2, A3B3). Assim, quando havia tentativas com um mesmo modelo, do tipo $A 1 B 1 B 2 B 3$, A1 era sempre o modelo, B1 era o $S c$ e B2 e B3, os $S i(\mathrm{~s})$. Em uma tentativa do tipo $A 1 B 1 B 2 B 4$, B1 era o $S c$ e B2 e B4, os $S i($ s). Em uma tentativa do tipo $A 1 B 1 B 3 B 4$, B1 era o $S c$ e B3 e B4 eram os $\mathrm{Si}(\mathrm{s})$. B4 (em AB) e C4 e D4 (em AC e AD) eram estímulos de distração, usados apenas no treino, para efeito de balanceamento das tentativas (ver Quadro 2).

Nesses estudos, exceto no Estudo 6, esteve em vigor uma contingência de quatro termos, que envolvia, em cada relação treinada, um modelo (estímulo condicional), um estímulo de comparação consistente (discriminativo), uma resposta e uma conseqüência não diferencial - a mudança na configuração dos estímulos. No Estudo 6, vigorou uma contingência de cinco termos. Além dos quatro elementos mencionados na contingência dos demais estudos, usou-se como elemento controlador da resposta ao modelo, conforme a situação, um estímulo contextual.

\section{Procedimento específico}

Havia treinos isolados (por exemplo, A1B1), anteriores à linha de base, em blocos de 36 tentativas, exceto no Estudo 7 (estes, constituídos de 24 tentativas). O treino seguia esta ordem, nos Estudos 1, 2, 4 e 6: A1B1, A2B2, A3B3 a $\mathrm{AB}$ misto, e assim por diante. Em seguida, eram aplicados os testes de Simetria e Equivalência. Nos Estudos 3, 5 e 7, a seqüência era diferente (ver sexta coluna do Quadro 1): cada bloco de treino era seguido, imediatamente, de um bloco de teste correspondente (exceto no Estudo 1). Por exemplo, após o treino A1B1, era aplicado o teste da relação inversa B1A1

Quadro 2. Demonstrativo do pareamento consistente usado como procedimento geral dos estudos: uma amostra da estruturação dos tipos de tentativas de um bloco de treino (AB).

\begin{tabular}{|c|c|c|c|c|c|}
\hline \multicolumn{6}{|c|}{ Treino AB } \\
\hline \multirow{2}{*}{$\begin{array}{l}\begin{array}{l}\text { Ordem de } \\
\text { tentativas }\end{array} \\
1\end{array}$} & \multirow{2}{*}{$\begin{array}{c}\text { Tipos de tentativas } \\
\text { A1 } B 1^{\mathrm{Sc}} \mathrm{B} 2 \mathrm{~B} 3^{\mathrm{Si}(\mathrm{s})}\end{array}$} & \multicolumn{4}{|c|}{ Estruturação das tentativas } \\
\hline & & A1 & $B 1$ & B2 & B3 \\
\hline 2 & $\mathrm{~A} 1 B 1^{\mathrm{Sc}} \mathrm{B} 2 \mathrm{~B} 4^{\mathrm{Si}(\mathrm{s})}$ & A1 & B2 & B4 & $B 1$ \\
\hline 3 & $\mathrm{~A} 1 B 1^{\mathrm{Sc}} \mathrm{B} 3 \mathrm{~B} 4^{\mathrm{Si}(\mathrm{s})}$ & A1 & B4 & $B 1$ & B3 \\
\hline 4 & $\mathrm{~A} 1 B 1^{\mathrm{Sc}} \mathrm{B} 2 \mathrm{~B} 3^{\mathrm{Si}(\mathrm{s})}$ & A1 & $B 1$ & B3 & B2 \\
\hline $\begin{array}{l}\mathrm{Sc} \\
\mathrm{Si}(\mathrm{s})\end{array}$ & $\begin{array}{l}\text { lo consistente } \\
\text { los inconsistentes }\end{array}$ & & & & \\
\hline
\end{tabular}

ou, após o bloco de treino da linha de base $A B$, era aplicado $o$ teste de simetria BA. Antes dos testes de equivalência $B C$ e $\mathrm{CB}$, eram feitas as duas revisões da linha de base (AB e AC). No Estudo 5, houve apenas três testes de Simetria e não foram programados testes de Equivalência. Foram apresentados testes de Seqüência. Nos testes, foram programados blocos de 36 tentativas, em todos os estudos - exceto no quinto (com 12) e no sétimo (com 24). Os estímulos que eram modelos no treino passaram a ser escolhas, com as suas posições invertidas. Não havia estímulos de distração. Assim, por exemplo, na Simetria BA (correspondente ao Treino AB), em uma tentativa do tipo B1A1 A2A3, B1 era o modelo, A1 era o $S c$ e A2 e A3, os $S i($ s). Não havia feedback para as respostas.

No Estudo 2, o treino, com fading, de cada relação isolada era seguido, imediatamente, do teste, sem fading, da relação inversa, e da Simetria correspondente, após a linha de base. O fading envolvia os modelos e os $S c(\mathrm{~s})$; consistia na remoção gradativa do sombreamento dos estímulos, desde o completo preenchimento até o simples contorno, ao longo das tentativas no sombreamento das figuras, ou seja, em sua apresentação preenchidas com uma tonalidade da cor azul que variava da mais forte até a mais fraca (o simples contorno), independentemente do desempenho do participante. Os $\mathrm{Si}$ (s) eram apresentados apenas com o contorno.

No Estudo 3, a antecipação dos testes (já descrita no estudo anterior) foi mantida, sem uso do fading.

No Estudo 4, o procedimento específico foi submeter os participantes da Condição 1 (com figuras usuais) ao treino na Condição 2 (com formas abstratas). Ainda, em submeter aos testes, nessa segunda condição, os sujeitos que participaram nos treinos correspondentes, na condição anterior, exceto um sujeito, por não ter atingido o critério nos treinos (ver observação no Quadro 1 e na Tabela 1).

No Estudo 5, o pareamento consistente foi usado nos treinos AB, CD e EF, seguidos da Simetria BA, DC e FE. Os modelos (dígitos), foram pareados, em fading, com estímulos de comparção (formas abstratas).

No Estudo 6, após os treinos $\mathrm{AB}, \mathrm{AC}$ e $\mathrm{AD}$ e testes $\mathrm{BC}$, $\mathrm{CB}, \mathrm{BD}, \mathrm{DB}, \mathrm{CD}, \mathrm{DC}$, sem estímulos do contexto, foi realizado o treino AD, seguido do teste de Simetria DA sob controle contextual.

Finalmente, no Estudo 7, com dois experimentos, os treinos envolveram apenas as relações condicionais $\mathrm{AB}$ e $\mathrm{AC}$ e testes de Simetria e Equivalência correspondentes - BA e $\mathrm{CA}$, e BC e CB. No Experimento 2, foi introduzido o fading.

No final dos estudos, os participantes foram entrevistados, com as seguintes perguntas: "O que você estava fazendo? Poderia me explicar?", "O que é isto? (o experimentador apontando para os estímulos na tela). As respostas verbais foram analisadas para verificar se correspondiam ao desempenho na tarefa motora durante as sessões.

\section{Resultados e Discussão}

A Tabela 1 apresenta os resultados em termos do número de exposições necessárias para o critério no treino e nos 
testes (Estudos 1, 2, 3, 4, 6 e 7), nos pós-testes de Equivalência (Estudo 3), e de Seqüência (Estudo 5).

\section{Desempenho consistente: condições de ocorrência/ fontes de controle}

Em geral, os resultados mostram que universitários sem história experimental prévia responderam escolhendo sempre os mesmos estímulos de comparação na presença dos modelos respectivos, sem a necessidade de conseqüências diferenciais, em cada tentativa, nas seguintes condições: 1- quando foram submetidos a um pareamento com o modelo de três escolhas; 2- quando esse pareamento envolvia um longo ou um curto delineamento de treino e de testes; 3- quando esse pareamento foi aliado ao fading do modelo e do Sc; 4- quando os testes foram apresentados somente depois de treinadas todas as relações condicionais (com atraso); 5- quando cada relação isolada, em cada treino, foi seguida, imediatamente, do teste da relação inversa isto é, sem atraso; 6- quando esse pareamento foi utilizado numa situação que envolvia estímulos usuais numa condição antecedente, para a demonstração, numa condição subseqüente, de novas discriminações entre estímulos não usuais; 7- quando nesse pareamento foram usados dígitos e formas abstratas como modelos e estímulos de comparação, respectivamente; 8- quando, finalmente, o pareamento consistente foi usado para estabelecer relações condicionais sob controle de estímulos contextuais, o que demonstrou uma ampliação da unidade básica de análise do comportamento (conforme proposto por Sidman, 1986), e um desempenho condicional de segunda ordem nesse formato de treino. $\mathrm{O}$ controle contextual já havia sido verificado anteriormente, documentado na literatura, porém, em decorrência do treino com reforçamento explicito para as escolhas, em cada tentativa, dos estímulos de comparação relacionados com os modelos correspondentes (ver, por exemplo, Assis \& Galvão, 1996; Lazar \& Kotlarchyk, 1986; Bush, Sidman \& de Rose, 1989; Gatch \& Osborne, 1989; Lynch \& Green, 1991; Wulfert \& Hayes, 1988).

Os resultados apontam que, além de adultos, crianças foram capazes também de exibir um desempenho consistente no treino sem reforçamento, mas sobretudo quando esse treino foi estruturado com fading.

Não obstante ter havido fracasso de alguns participantes nos testes, com bastante variabilidade (ver Estudo 7), se atentarmos para a linha de base, apontamos que os resultados, vistos isoladamente ou em conjunto, atestam um fato: na ausência de reforçamento diferencial, em cada tentativa, outras fontes exercem controle sobre a resposta. São essas fontes: 1- a exposição repetida ou reexposição às tentativas de um bloco de treino (que se mostrou elevada nos treinos iniciais, e decrescente nos treinos posteriores); 2- o arranjo das tentativas, de modo a tornar altamente provável a escolha do $S c$, em detrimento da escolha de quaisquer $\mathrm{Si}$ (s); 3- o recurso da apresentação do modelo e respectivo $S c$ com fading; 4- a antecipação dos testes, de modo a possibilitar um não atraso de sua apresentação, em relação aos treinos; 5- a manipulação da natureza dos estímulos em condições diferentes, garantindo a formação de discriminações condi-

Tabela 1. Resultados obtidos nos Estudos 1, 2, 3, 4, 5, 6 e 7 (Baptista \& Assis, 1995; Assis, Baptista, Damin \& Álvares, 1997; Damin, Assis \& Baptista, 1998; Barros, Baptista \& Assis, 1998; Lima, Assis, Baptista \& Sampaio, 1999; Assis, Baptista, Kato \& Alves, 2000; Álvares, Assis, Esteves \& Sampaio, submetido): número de exposições necessárias para o critério no treino de discriminações condicionais e porcentagem de acertos nos testes (e pós-testes) de Simetria e Equivalência (último bloco) e de Seqüência.

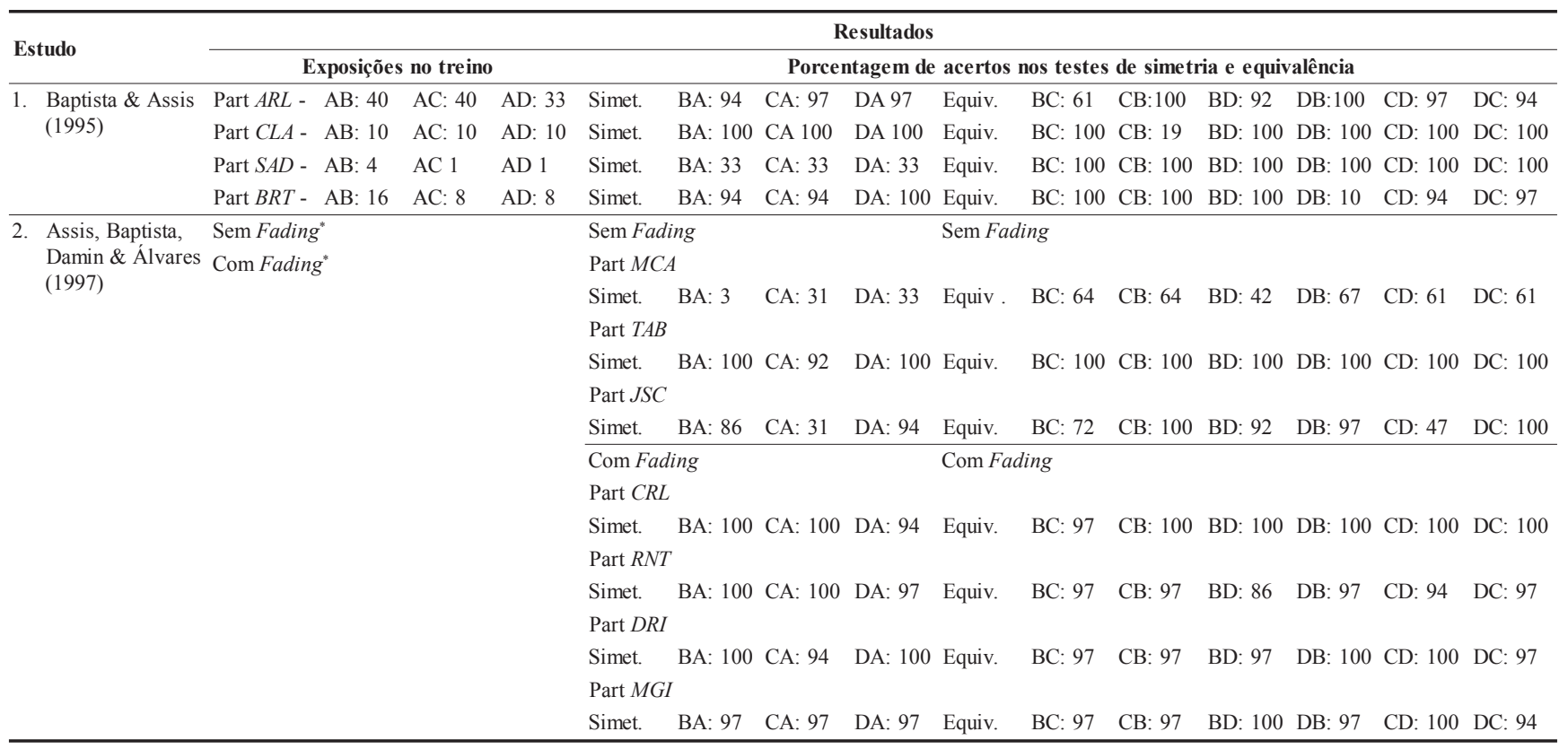

* Indica que nas duas condições (com e sem fading) os sujeitos formaram as relações condicionais após o máximo de exposições às tentativas. Simet. $=$ Simetria Equiv. $=$ Equivalência Part. $=$ Participante 
Tabela 1. (Continuação)

\begin{tabular}{|c|c|c|c|c|c|c|c|c|c|c|c|c|c|c|c|c|}
\hline \multirow{3}{*}{ Estudo } & \multicolumn{16}{|c|}{ Resultados } \\
\hline & \multirow{2}{*}{\multicolumn{4}{|c|}{ No. de exposições no treino }} & \multicolumn{12}{|c|}{ Porcentagem de acertos nos testes e pós-testes de simetria e equivalência } \\
\hline & & & & & \multicolumn{2}{|c|}{ Teste } & \multicolumn{2}{|c|}{ Pós teste } & \multicolumn{4}{|c|}{ Teste } & \multicolumn{4}{|c|}{ Pós teste } \\
\hline \multirow[t]{16}{*}{ 3. Dan } & Part $J O A$ & & & & & & & & & & & & & & & \\
\hline & Treino $A$ & AB: 16 & & & Simet. & BA: 100 & Simet. & BA: 100 & Equiv. & BC: 100 & CB: 100 & CD: 92 & Equiv. & BC: 100 & CB: 100 & CD: 100 \\
\hline & & AC: 9 & & & & CA: 100 & & CA: 100 & & BD: 97 & DB: 97 & DC: 100 & & BD: 100 & DB: 100 & DC: 100 \\
\hline & & AD: 7 & & & & DA: 94 & & DA: 100 & & & & & & & & \\
\hline & Part $M A$ & & & & & & $(* *)$ & & & & & & $(* *)$ & & & \\
\hline & Treino $A$ & AB: 11 & & & Simet. & BA:100 & & & Equiv. & BC: 100 & CB: 100 & CD: 100 & & & & \\
\hline & & AC: 6 & & & & CA: 100 & & & & BD: 100 & DB: 100 & DC: 100 & & & & \\
\hline & & AD: 8 & & & & DA: 100 & & & & & & & & & & \\
\hline & Part SEK & & & & & & $(* *)$ & & & & & & $(* *)$ & & & \\
\hline & Treino $A$ & AB: 10 & & & Simet. & BA:100 & & & Equiv. & BC: 100 & CB: 100 & CD: 97 & & & & \\
\hline & & AC: 7 & & & & CA: 100 & & & & BD: 100 & DB: 100 & DC: 100 & & & & \\
\hline & & AD: 9 & & & & DA: 94 & & & & & & & & & & \\
\hline & Part $L U C$ & & & & & & & & & & & & & & & \\
\hline & Treino $A$ & AB: 8 & & & Simet. & BA: 92 & Simet. & BA: 94 & Equiv. & BC: 100 & CB: 100 & CD: 100 & Equiv. & BC: 100 & CB: 100 & CD: 100 \\
\hline & & AC: 5 & & & & CA: 100 & & CA: 100 & & BD: 100 & DB: 100 & DC: 100 & & BD: 100 & DB: 100 & DC: 100 \\
\hline & & AD: 5 & & & & DA: 92 & & DA: 94 & & & & & & & & \\
\hline \multirow{17}{*}{$\begin{array}{l}\text { 4. } \text { Barros, } \\
\text { Baptista \& } \\
\text { Assis (1998) }\end{array}$} & Condiçã & $\tilde{a} o 1$ & Condiçc & & Condiçâa & & Condiçà & & Condiçã & & & & Condiça & 2 & & \\
\hline & Part $S M$ & & & & & & & & & & & & & & & \\
\hline & Treino $A$ & AB: 34 & Treino & $\mathrm{AB}: 40$ & Simet. & BA: 100 & Simet. & BA: 100 & Equiv. & BC: 100 & CB: 100 & CD: 17 & Equiv. & BC: 100 & CB: 100 & CD: 100 \\
\hline & & AC: 09 & & AC: 33 & & CA: 100 & & CA: 97 & & BD: 100 & DB: 100 & DC: 100 & & BD: 100 & DB:100 & DC: 100 \\
\hline & & AD: 11 & & AD: 35 & & DA: 100 & & DA: 100 & & & & & & & & \\
\hline & Part ESK & & $(* * *)$ & & & & & & & & & & & & & \\
\hline & Treino $A$ & AB: 40 & Treino & $\mathrm{AB}: 40$ & Simet. & BA: 00 & & & & & & & & & & \\
\hline & & AC: 43 & & AC: 40 & & CA: 00 & & & & & & & & & & \\
\hline & & AD: 28 & & AD: 40 & & DA: 00 & & & & & & & & & & \\
\hline & Part ISA & & & & & & & & & & & & & & & \\
\hline & Treino $A$ & AB: 11 & Treino & AB: 10 & Simet. & BA: 94 & Simet. & BA: 97 & Equiv. & BC: 100 & CB: 100 & CD: 97 & Equiv. & BC: 100 & CB: 100 & CD: 100 \\
\hline & & AC: 7 & & AC: 6 & & CA: 97 & & CA: 100 & & BD: 100 & DB: 100 & DC: 100 & & BD: 100 & DB: 100 & DC: 100 \\
\hline & & AD: 5 & & $\mathrm{AD}: 4$ & & DA: 97 & & DA: 100 & & & & & & & & \\
\hline & $\overline{\text { Part } E L I}$ & & & & & & & & & & & & & & & \\
\hline & Treino $A$ & AB: 22 & Treino & $\mathrm{AB}: 32$ & Simet. & BA: 97 & Simet. & BA: 92 & Equiv. & BC: 100 & CB: 100 & CD: 100 & Equiv. & BC: 100 & CB: 100 & CD: 100 \\
\hline & & AC: 24 & & AC: 16 & & CA: 100 & & CA: 97 & & BD: 97 & DB: 100 & DC: 97 & & BD: 97 & DB: 100 & DC: 97 \\
\hline & & AD: 8 & & $\mathrm{AD}: 4$ & & DA: 100 & & DA: 100 & & & & & & & & \\
\hline
\end{tabular}

** Indica os participantes que não foram submetidos aos pós-testes por não terem sido encontrados depois de sua participação no estudo.

Simet. $=$ Simetria $\quad$ Equiv. $=$ Equivalência $\quad$ Part. $=$ Participante $\quad$ Situação $1=$ sem estímulos contextuais

Situação 2 = com estímulos contextuais (cores verde e vermelho)

*** Indica que esse participante não atingiu o critério mesmo depois de um número máximo de exposições às tentativas desses treinos. Como não demonstrou nenhuma das relações simétricas, após o critério nas linhas de base correspondentes, ele não foi submetido aos testes de equivalência.

cionais entre estímulos não usuais, após exposição bem-sucedida a treinos com estímulos usuais.

\section{Relação Entre os Estudos: Alguns Aspectos}

O Estudo 1, além de ter confirmado o de Harrison e Green (1990), constituiu uma ampliação do procedimento usado por esses autores, no que respeita ao número de classes programadas e ao pareamento consistente de estímulos sem conseqüências diferenciais. Em relação ao Estudo 1, o Estudo 2 mostrou a importância do fading, aliado ao pareamento consistente, na formação de discriminações condicionais sem conseqüências diferenciais. Os Estudos 5 e 7 (Experimento 2) continuaram demonstrando essa importância, evidenciando o uso do fading como uma variável eficaz para o desempenho sem reforçamento explícito; esse uso foi, entre- tanto, adicionado à antecipação dos testes, o que minimizou o atraso dos mesmos, em comparação com os demais estudos, exceto o Estudo 3, em que a antecipação foi introduzida. A estratégia do ensino, numa condição inicial, de discriminações condicionais entre estímulos usuais, sem reforçamento, como requisito para o ensino, numa condição posterior, de discriminações entre estímulos não usuais, também sem reforçamento, foi verificada como pertinente no Estudo 4. No Estudo 6, houve o controle por estímulos contextuais. O Estudo 7, mostrou ser possível, nas condições do delineamento utilizado, a obtenção de discriminações condicionais sem conseqüências diferenciais, em crianças; podemos, além disso, considerar os resultados do Experimento 2 como indicativos de que a manipulação do fading foi crucial, para essas discriminações, quando estavam envolvidas relações entre estímulos desconhecidos. 
Tabela 1. (Continuação)

\begin{tabular}{|c|c|c|c|c|c|c|c|c|c|c|c|c|}
\hline \multirow{2}{*}{ Estudo } & \multicolumn{12}{|c|}{ Resultados } \\
\hline & \multicolumn{2}{|c|}{ No. de exposições no treino } & \multicolumn{10}{|c|}{ Porcentagem de acertos nos testes de simetria e equivalência } \\
\hline 5. Lima, Assis, & Part $A N D$ & & & & & & & & & & & \\
\hline Baptista \& & Treino & AB: 04 & Simet. & BA: 100 & & & & & & & & \\
\hline & & CD: 04 & & DC: 100 & & & & & & & & \\
\hline & & EF: 04 & & FE $: 100$ & & & & & & & & \\
\hline & Part CHIA & & & & & & & & & & & \\
\hline & Treino & AB: 04 & Simet. & BA: 97 & & & & & & & & \\
\hline & & CD: 04 & & DC: 97 & & & & & & & & \\
\hline & & EF: 04 & & FE: 97 & & & & & & & & \\
\hline & Part ELI & & & & & & & & & & & \\
\hline & Treino & AB: 04 & Simet. & BA: 97 & & & & & & & & \\
\hline & & CD: 07 & & DC: 97 & & & & & & & & \\
\hline & & EF: 04 & & FE: 97 & & & & & & & & \\
\hline & $\begin{array}{l}\text { Part } F A B \\
\end{array}$ & & & & & & & & & & & \\
\hline & Treino & AB: 04 & Simet. & BA: 83 & & & & & & & & \\
\hline & & CD: 05 & & DC: 97 & & & & & & & & \\
\hline & & EF: 04 & & FE: 97 & & & & & & & & \\
\hline & Part $M A R$ & & & & & & & & & & & \\
\hline & Treino & AB: 04 & Simet. & BA: 100 & & & & & & & & \\
\hline & & CD: 04 & & DC: 100 & & & & & & & & \\
\hline & & EF: 04 & & FE: 100 & & & & & & & & \\
\hline \multirow{16}{*}{$\begin{array}{l}\text { 6. Assis, Baptista, } \\
\text { Kato \& Alves } \\
\text { (2000) }\end{array}$} & Part $N E T$ & & Situação & & Situação 2 & & Situaçã & & & & Situação 2 & \\
\hline & Treino & AB: 01 & Simet. & BA: 100 & Simet. & DA 97 & Equiv. & BC: 33 & CB: 33 & CD: 38 & Equiv. DB: 33 & DC: 50 \\
\hline & & AC: 01 & & CA: 100 & & & & BD: 00 & DB: 33 & DC: 55 & & \\
\hline & & AD: 02 & & DA: 100 & & & & & & & & \\
\hline & Part ALIN & & Situação & & Situação 2 & & Situaçã & & & & Situação 2 & \\
\hline & Treino & AB: 01 & Simet. & BA: 97 & Simet. & DA: 97 & Equiv. & BC: 67 & CB: 11 & CD: 67 & Equiv. DB: 64 & DC: 45 \\
\hline & & AC: 01 & & CA: 100 & & & & BD: 33 & DB: 64 & DC: 61 & & \\
\hline & & AD: 03 & & DA: 100 & & & & & & & & \\
\hline & Part $K A R$ & & Situação & & Situação 2 & & Situaçã & & & & Situação 2 & \\
\hline & Treino & AB: 02 & Simet. & BA: 33 & Simet. & DA: 31 & Equiv. & BC: 33 & CB: 33 & CD: 45 & Equiv. DB: 50 & DC: 28 \\
\hline & & AC: 01 & & CA: 33 & & & & BD: 33 & DB: 33 & DC: 61 & & \\
\hline & & AD: 03 & & DA: 33 & & & & & & & & \\
\hline & Part $P A U L$ & & Situação & 1 & Situação 2 & & Situaçã & & & & Situação 2 & \\
\hline & Treino & AB: 01 & Simet & BA: 97 & Simet & DA: 100 & Equiv & BC: 33 & CB: 64 & CD: 100 & Equiv. $\quad$ DB: 97 & DC: 42 \\
\hline & & AC: 01 & & CA: 97 & & & & BD: 33 & DB: 100 & DC: 97 & & \\
\hline & & AD: 03 & & DA: 97 & & & & & & & & \\
\hline
\end{tabular}

Os treinos do Estudo 5 foram realizados com fading.

Os dados dos estudos 5 e 6 referem-se à linha de base (treino misto).

\section{Relevância conceitual e controle por fontes alternativas}

Pelo menos em termos hipotéticos, os estudos têm relevância teórica. O procedimento geral e os resultados obtidos contribuem para a discussão do papel do reforço. Analistas do comportamento parecem divergir quanto à definição de reforço (ou estímulo reforçador). Segundo Reynolds (1975), "um estímulo é reforçador se, ao ser apresentado, em conseqüência de uma resposta, produzir o aumento da probabilidade de sua ocorrência no futuro" (p. 9). Há um entendimento similar em Skinner (1953/1981), Catania (1968) e Sulzer-Azaroff e Mayer (1977). Outros autores, como Schlinger Jr., Blakely, Fillhard e Poling (1991), consideram na definição de reforço, o tempo entre a resposta e o estímulo; ou seja, para ser reforçador, é preciso que um estímulo seja apresentado imediatamente após um desempenho, aumentando a freqüência ou a taxa de respostas desse de- sempenho. Para Schoenfeld (1995), a função reforçadora de qualquer estímulo implica que sejam tidos em conta, como parâmetros, as características especiais do sujeito, a intensidade do estímulo, a modalidade sensorial e os esquemas de aplicação.

Apesar das divergências quanto ao reforço, a literatura documenta uma tradição já bem estabelecida de seu uso em experimentos de discriminações condicionais. O procedimento geral e específico dos estudos descritos no presente trabalho (ver Quadro 1), bem como o procedimento dos experimentos que lhes serviram de base, introduzindo o que analisamos como treino por consistência de estímulos, parecem ser alternativos a essa tradição e sugerem uma análise de outras fontes de controle do comportamento, em relação ao controle exercido pelo reforço. Essas fontes são importantes, para uma discussão de reforço a partir da proposta de Schlinger Jr. e colaboradores (1991), isto é, que considera a temporalidade entre resposta e estímulo. 
Tabela 1. (Continuação)

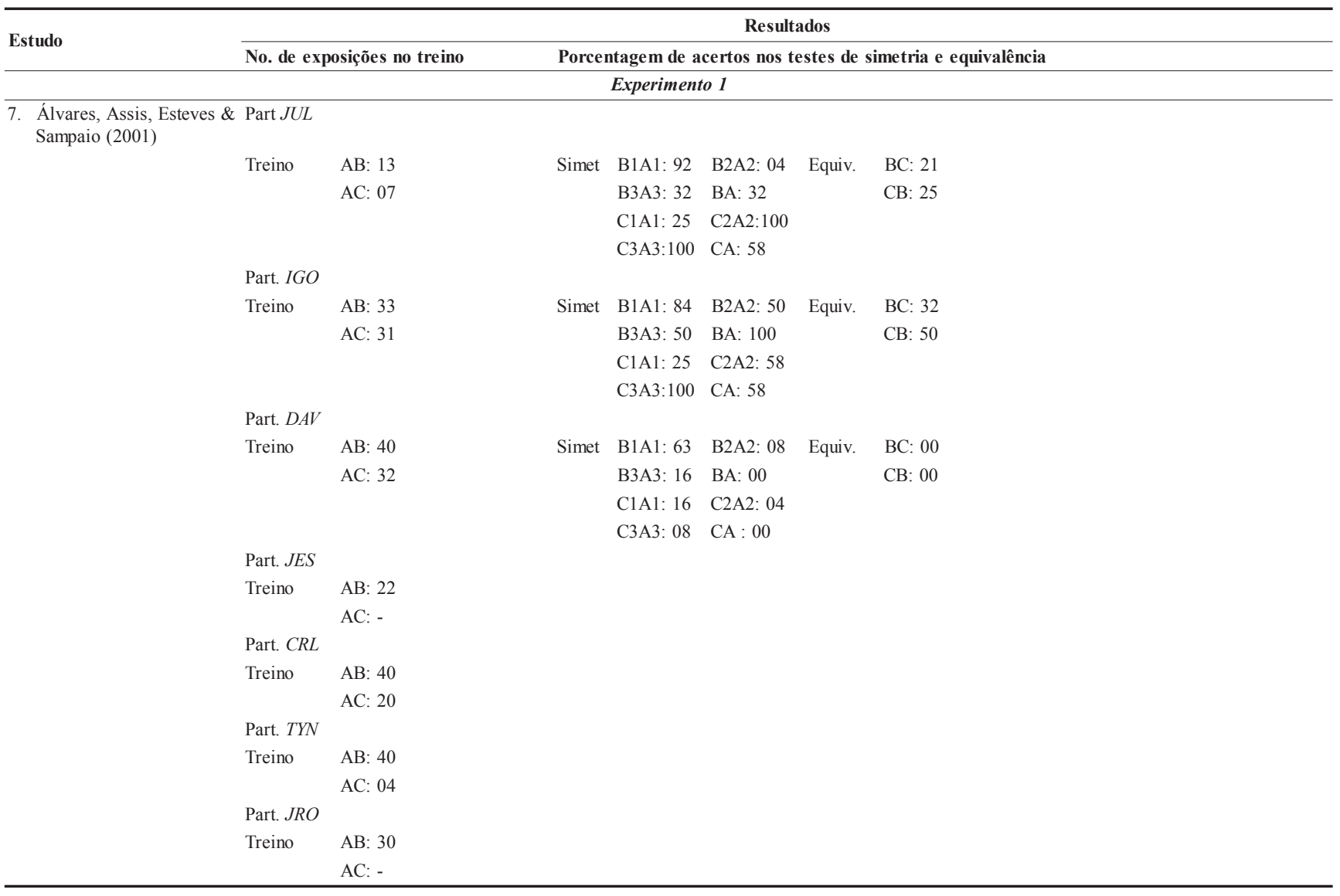

\section{Pareamento Modelo-Sc e Modelo-Si}

Nos estudos, não eram liberadas no treino de discriminações condicionais, quaisquer conseqüências diferenciais para as respostas; os acertos e os erros produziam uma mesma conseqüência, não diferencial, que era a mudança na configuração dos estímulos na tela. Por exemplo, numa tentativa do tipo $\mathrm{A} 1 \mathrm{~B} 1 \mathrm{~B} 2 \mathrm{~B} 3$, o responder ao modelo $\mathrm{A} 1$ (quando sozinho), produzia o seu rápido desaparecimento, seguido de seu reaparecimento juntamente do $S c(B 1)$ e dos $S i(s)$ $\mathrm{B} 2$ e B3; e o responder a $B 1$ ou a $\mathrm{B} 2$ ou a $\mathrm{B} 3$ produzia o desaparecimento do modelo e dos estímulos de comparação, e o reaparecimento posterior do modelo sozinho. Em outra tentativa, a resposta a $\mathrm{A} 1$, bem como a $B 1$, produziam a mesma alteração da configuração dos estímulos, e assim por diante. Portanto, durante um bloco de tentativas, a única conseqüência para o desempenho era essa mudança na configuração dos estímulos, ou seja, no arranjo dos tipos de tentativas para cada modelo (A1B1 B2 B3; A1B1 B2B4; A1B1 $\mathrm{B} 3 \mathrm{~B} 4)$. A conseqüência funcionava apenas para o avanço das tentativas de um bloco, havendo, com esse avanço, a garantia de apresentação de todos os tipos de tentativas. Essa conseqüência, pelo menos nas tentativas iniciais, era inócua para a discriminação do $S c$ (ao qual o participante deveria responder), ou para a discriminação dos $S i$ (s) (que ele deveria rejeitar).
Caso o participante atingisse o critério (um erro apenas), num único bloco de treino (por exemplo, A1B1), era exposto ao bloco seguinte (A2B2), e assim por diante. Não tendo atingido o critério, após uma única exposição ao bloco, o participante era reexposto ao mesmo até 10 vezes. E se persistisse no erro, ele passava para o treino seguinte. Portanto, atingindo o critério ou não, a passagem de um bloco de treino para o bloco do treino seguinte era obrigatória, e isso ocorria como se o treino seguinte fosse continuação do anterior, isto é, como se ambos constituíssem um único bloco, uma vez que o intervalo de tempo entre o fim do bloco de um treino e o começo do bloco do treino seguinte era igual ao intervalo de tempo entre as tentativas. Também, os tipos de tentativas em cada treino seguinte eram idênticos aos dos treinos anteriores, ou seja, as mudanças nas configurações dos estímulos eram as mesmas. O intervalo de tempo não constituía, portanto, um estímulo discriminativo para o desempenho consistente. Poderia sê-lo, talvez, se fosse maior, diferenciado em relação ao intervalo entre as tentativas.

Os participantes que formaram as relações condicionais provavelmente discriminaram a mudança do modelo quando mudava o treino (por exemplo, a mudança de A1 para A2, respectivamente no treino A1B1 e A2B2). Também, o seu desempenho continuou ocorrendo em cada novo formato de treino, mas não há indícios de que possamos tomar essa mudança como um Sd para esse desempenho, pois, a 
Tabela 1. (Conclusão)

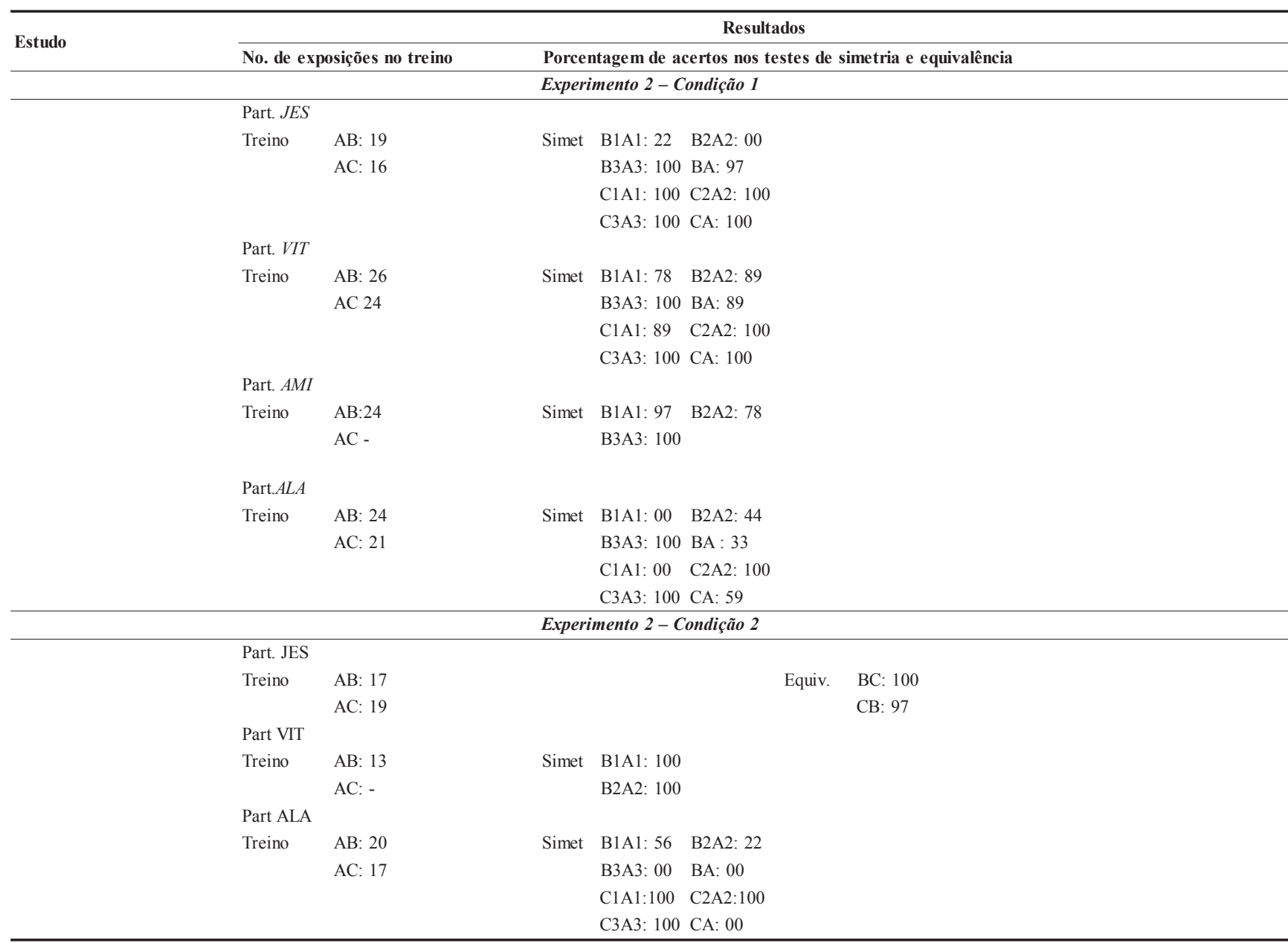

- O participante JES não alcançou o critério nas linhas de base. Os participantes CRL, TYN e JRO não alcançaram o critério nas linhas de base e abandonaram o experimento.

- O participante AMI abandonou o experimento após ter sido submetido ao teste de Simetria B3A3.

- Os treinos dos Estudo 7 foram realizado com fading

passagem de um treino para o seguinte ocorria independentemente dos acertos e dos erros. Somente depois de várias exposições às tentativas de treino (do treino inicial), é que os participantes passaram a errar com menor freqüência, conforme indicaram alguns relatos pós-experimentais. A reexposição foi programada como uma variável crítica que pudesse garantir a formação de discriminações condicionais, pelo menos nos treinos iniciais, uma vez que, nesses treinos, a consistência do pareamento dos modelos e respectivas escolhas poderia não ser suficiente para gerar tais discriminações, como ficou demonstrado. $\mathrm{O}$ arranjo das tentativas foi feito de tal modo que somente depois de todos os tipos de tentativas terem sido apresentados é que a consistência do pareamento de um dado modelo com seu respectivo $S c$ era efetivamente discriminada, em relação à inconsistência do pareamento desse modelo com quaisquer $\mathrm{Si}(\mathrm{s})$ correspondentes. Em outras palavras, o arranjo das tentativas constituiu uma forma de restringir o controle do pareamento $\mathrm{Mo}$ delo-Sc. Em alguns relatos pós-experimentais, os participantes sinalizaram a "descoberta" da consistência do pareamento
Modelo-Sc versus inconsistência ModeloSi(s), o que foi concordante com o seu desempenho nas sessões, decorridos alguns blocos de treino (ver Baptista \& Assis, 1995). Porém, foram incapazes de precisar quando, de fato, ocorreu essa discriminação.

\section{Reexposição às Tentativas de Treino: Situação de Erro e Situação de Acerto}

A análise do papel que a reexposição deva ter desempenhado nos estudos sugere que consideremos duas situações experimentais prováveis, embora como hipóteses (ver Quadro 3), que caracterizam diferentes desempenhos de dois participantes. Suponhamos duas situações (Situação 1, que chamamos situação de erro, com uma possibilidade, e Situação 2, de acerto, com duas possibilidades). Na possibilidade da Situação 1, o participante poderia errar em cada bloco de treino (por exemplo, A1B1), após o máximo de reexposições às tentativas, e continuar errando até ser submetido a todos os blocos (no máximo). Nesse caso, ele seria reexposto 
a um total de 1.440 tentativas, pois não passaria para a revisão da linha de base antecedente aos testes. O desempenho indicaria o controle pela relação Modelo-Si, ou a estratégia da "descoberta" da inconsistência do experimento. Na segunda situação, de acerto, haveria duas possibilidades. Primeira: um participante acertaria depois de uma única exposição aos blocos, provavelmente, em cada treino (por exemplo, A1B1), o que evidenciaria, assim, o uso da estratégia da "descoberta" da consistência do experimento, sob controle pela relação Modelo-Sc. Uma vez tendo o participante aprendido a acertar, no primeiro bloco, provavelmente, ele continuaria acertando até o final do experimento, bastando uma única exposição. Ele seria reexposto a um total de 180 tentativas (incluindo as 36 tentativas de revisão de linha de base) - uma significativa economia de exposição (12,5\%), relativamente à exposição na situação anterior. Segunda possibilidade (possível, mas muito pouco provável): um participante poderia acertar somente depois de um máximo de reexposições iniciais (no décimo bloco) e na revisão de linha de base (quinto bloco) e, assim, nos demais treinos. Ele seria exposto a um total de 1.620 tentativas (incluindo as 180 de revisão de linha de base).

Em termos de economia de exposição, a primeira possibilidade da Situação 2 seria a melhor de todas. Mas, se comparadas a única possibilidade da Situação 1 com a possibilidade 2 da Situação 2, observamos que ocorreria um elevado número de reexposições em ambas, não obstante como efeitos de opostas relações de controle. O pareamento Modelo $S c$ seria efetivo, mas conforme a primeira possibilidade da segunda situação. A reexposição às tentativas, quer quando o participante errasse quer quando acertasse, dado que era prevista no delineamento, poderia ser interpretada como favorecedora da utilização das estratégias referidas - a da discriminação da inconsistência e da consistência do experimento (primeira e segunda situação, respetivamente). Portanto, a reexposição seria uma variável importante enquanto oportunidade para o responder sob controle dos dois tipos de relação. O participante que errasse sempre ao longo do treino, poderia levantar a hipótese de que quaisquer $S i(\mathrm{~s})$ seriam os estímulos aos quais ele deveria responder, em detrimento dos $S c(\mathrm{~s})$. O teste dessa hipótese, passível de se verificar pelo prosseguimento do desempenho incorreto, seria possibilitado pela oportunidade garantida pela reexposição. Também, o participante que acertasse, poderia fazê-lo tendo em conta a hipótese de que deveria responder ao $S c$, em detrimento de a quaisquer $\mathrm{Si}(\mathrm{s})$.

Se, na situação de erro, a reexposição seria passível de propiciar um controle efetivo pela relação Modelo-Si, a mesma seria inócua para o controle pela relação Modelo-Sc, nessa situação, pois a continuação do responder a um ou a mais $\mathrm{Si}$ (s) ao longo do treino indicaria isso. O Modelo-Si seria incompatível com o controle Modelo-Sc, a não ser que houvesse a ação de alguma variável não programada. Se, na situação de acerto (tendo em conta a Possibilidade 1), a reexposição contribuiria para restringir o controle pela relação Modelo-Sc, a mesma seria inócua para o controle Modelo-Si, atestado pelas escolhas constantes do $S c$, em detrimento
Quadro 3. Demonstrativo do número de reexposições às tentativas do treino $\mathrm{AB}$, em duas situações hipotéticas, como amostra para análise do controle pela relação Modelo-Si e Modelo-Sc.

\begin{tabular}{|c|c|c|c|}
\hline \multicolumn{2}{|c|}{$\begin{array}{l}\text { Situação } 1 \text { - Erro } \\
\text { Controle pela Relação Modelo-Si }\end{array}$} & \multicolumn{2}{|c|}{$\begin{array}{c}\text { Situação } 2 \text { - Acerto } \\
\text { Controle pela relação Modelo-Sc }\end{array}$} \\
\hline \multicolumn{2}{|c|}{$\begin{array}{c}\text { Possibilidade Única } \\
\text { Treino AB / No. de Tentativas }\end{array}$} & \multicolumn{2}{|c|}{$\begin{array}{c}\text { Possibilidade } 1 \\
\text { Treino AB / No. de Tentativas }\end{array}$} \\
\hline & & & No. de Tentativas \\
\hline A1B1 & $36 \times 10=360$ & A1B1 & $36 \mathrm{X} 1=36$ \\
\hline $\mathrm{A} 2 \mathrm{~B} 2$ & $36 \times 10=360$ & $\mathrm{~A} 2 \mathrm{~B} 2$ & $36 \times 1=36$ \\
\hline A3B3 & $36 \times 10=360$ & A3B3 & $36 \times 1=36$ \\
\hline \multirow[t]{13}{*}{ AB Misto } & $36 \times 10=360$ & AB Misto & $36 \times 1=36$ \\
\hline & Sub-total: 1.440 & & Sub-total: 144 \\
\hline & & $\begin{array}{l}\text { Revisão da Linha } \\
\text { de Base AB }\end{array}$ & $36 \times 1=36$ \\
\hline & & & Total $=180$ \\
\hline & & \multicolumn{2}{|c|}{$\begin{array}{c}\text { Possibilidade } 2 \\
\text { Treino AB / No. de Tentativas } \\
\end{array}$} \\
\hline & & \multicolumn{2}{|r|}{ No. de Tentativas } \\
\hline & & A1B1 & $36 \times 10=360$ \\
\hline & & $\mathrm{A} 2 \mathrm{~B} 2$ & $36 \times 10=360$ \\
\hline & & A3B3 & $36 \times 10=360$ \\
\hline & & AB Misto & $36 \times 10=360$ \\
\hline & & & Sub-total: 1.440 \\
\hline & & $\begin{array}{l}\text { Revisão da Linha } \\
\text { de Base AB }\end{array}$ & $36 \times 5=180$ \\
\hline & & & Total $=1.620$ \\
\hline
\end{tabular}

- Na Situação 1: desempenho com erros, em cada bloco de 36 tentativas do treino $\mathrm{AB}$, após o máximo de reexposições (10).

- Na Situação 2 - Possibilidade 1: desempenho com acertos, após uma única exposição a cada bloco do treino $\mathrm{AB}$ e na primeira exposição no treino misto (linha de base). Possibilidade 2: desempenho com acertos, após o máximo de reexposições (10) no treino $\mathrm{AB}$ e na revisão de linha de base (quinto bloco).

dos $\mathrm{Si}(\mathrm{s})$. Os resultados sugerem que, apesar de seu possível efeito facilitador, nas duas situações, a reexposição pode ter atuado mais favoravelmente nos participantes cujo desempenho estaria relacionado à situação de acerto do que aqueles que se enquadrariam à situação de erro. Essa suposição é concordante com uma observação apontada no Estudo 1 (Baptista \& Assis, 1995), ou seja, que os acertos "produziam um avanço mais rápido de um treino para o seguinte do que os erros" (p. 179).

O efeito facilitador da reexposição poderia ser função de variáveis outras, não programadas e não controladas, como, por exemplo, as relativas à história comportamental dos participantes da segunda situação, o que caracterizaria sua maior sensibilidade a esse efeito, em relação aos participantes da primeira situação. Para os participantes da Situação 2, o efeito da reexposição pode ter sido reforçadora, por eles terem experimentado e respondido com acertos freqüentes em situações similares, no passado.

\section{Conseqüência com "Atraso" Versus Refoçamento Imediato}

Tendo em conta esse possível efeito reforçador da reexposição, podemos analisá-lo então como sugestivo para uma 
concepção alternativa àquela de estímulo reforçador proposta por Schlinger Jr. e colaboradores. (1991), isto é, enquanto estímulo que segue imediatamente um desempenho, aumentando a sua freqüência. Caso ocorresse de fato, esse efeito reforçador ter-se-ia verificado, provavelmente, depois de repetidas exposições às tentativas dos treinos iniciais e, portanto, com atraso em relação ao desempenho que produziu essas reexposições. Considerando tal atraso, apontamos que tal efeito seja interpretado como uma conseqüência reforçadora, mas não imediata, isto é, após cada tentativa de treino. E sugerimos que esta interpretação (que, entretanto, se limita aos nossos estudos), seja vista como uma contribuição para ampliar a discussão do conceito de reforço, tendo por base a sua definição sugerida por Schlinger Jr. e colaboradores (1991).

\section{Algumas implicações educacionais}

Pré-Treino e Familiarização com a Situação de Ensino. Um dos aspectos do delineamento do procedimento geral dos estudos descritos foi o Pré-Treino - fase em que os experimentadores tinham como objetivo familiarizar os participantes com a situação experimental e com o procedimento nas fases seguintes, através de instruções mínimas na tela e, quando necessário, através de demonstrações. Em sala de aula, um procedimento idêntico pode e deve estar envolvido. Em sala de aula, nem sempre o professor tem, no contato inicial com seus alunos, a prática de lhes prover a devida familiarização com a situação geral desse ambiente tanto em seu aspecto físico quanto social. Nem, também, a familiarização com aspectos voltados especificamente para a prática de ensino - o programa das disciplinas, o plano da aula e a dinâmica de sua implementação, dentre outros. A familiarização pode propiciar o responder ao novo ambiente e, ainda, a esses aspectos da prática de ensino. Particularmente, no que respeita ao ensino, uma vez que o aluno comece a participar do seu processo, é provável que o faça nas etapas posteriores.

Se a familiarização é importante nas práticas de ensino em que o professor usa tradicionalmente reforçamento diferencial para o desempenho de seus alunos, podemos tomála como mais pertinente ainda para aquelas práticas em que o feedback é não diferencial, como assim foi o procedimento geral que caracterizou os estudos relatados. Lembramos que, no Pre-Treino e no Treino desses estudos, os participantes não recebiam qualquer informação que facilitasse $o$ seu desempenho. Eles eram simplesmente orientados (no PréTreino) sobre como usar o "matching-to-sample", sobre o objetivo do experimento, o número médio das sessões e sua duração, e o que deveriam fazer quando cada sessão terminasse. A orientação fora programada para ter a função de impedir, nas etapas posteriores, um desempenho que refletisse o que poderia ser considerado insensibilidade às contingências dispostas no experimento, dado que não havia, em cada tentativa, conseqüências diferenciais explícitas para a tarefa. As respostas durante as sessões e algumas verbalizações dos participantes, por exemplo, do Estudo 1 (Baptista \& Assis, 1995) indicaram ter sido verificada essa função.
Treino sem Reforçamento e Ensino para Autonomia. Outro importante aspecto que pode ter implicações educacionais, relaciona-se com o procedimento geral de treino sem reforçamento diferencial, conforme descrito. Trata-se da chamada autonomia intelectual, que uma prática de ensino bem planejada e executada pode acarretar ("arranjo de contingências de reforçamento que aceleram a aprendizagem" Skinner, 1969, p. 15). Em outras palavras: emissão de comportamentos úteis ou bem-sucedidos no âmbito da interação professor-aluno e, sobretudo, como decorrência dessa interação, manifestada no futuro. Ou, ainda, auto-governo, independência intelectual - tomada de decisões por conta própria que produzam soluções de problemas (ver Skinner, 1953/ 1981). O procedimento geral dos estudos descritos era propenso a produzir autonomia; e se ocorresse, seria evidenciada ao longo das sessões e mesmo, provavelmente, após os experimentos - enquanto um produto do arranjo das tentativas de treino em que, dentre outros aspectos, estaria incluída a reexposição.

A reexposição permitiria um contato freqüente dos participantes com a configuração dos estímulos na tela, à semelhança do contato freqüente dos alunos com um texto, em sala de aula, na ausência do professor; ou, mesmo, na presença deste, sem que pudesse prover a sua assistência. Se, por um lado, os participantes não dispunham, em cada tentativa de um bloco, de feedback diferencial explícito e imediato para o seu responder, podiam, por outro lado, obtê-lo, após o término do bloco, ou, conforme o critério, após várias reexposições ao bloco na mesma ou em sessões posteriores. Portanto, a estruturação ou arranjo das tentativas de treino era passível de produzir um desempenho com autonomia, caraterizado pela tomada de decisões próprias; caso houvesse tal desempenho, este poderia gerar conseqüências reforçadoras. Tal como nesses estudos, em sala de aula, a programação do ensino pode conduzir os alunos à descoberta de soluções apropriadas para os problemas propostos pelo professor, ou levá-los a emitir respostas corretas para as questões postas, ou discriminar, por exemplo, se um texto programado e usado como conteúdo de aprendizagem e sua posterior avaliação, é repleto de inconsistências ou tem coerência suficiente para fomentar a sua leitura.

Sugerimos, com a presente análise, que procedimentos de laboratório podem produzir resultados interessantes com implicações conceituais e metodológicas. Particularmente, no que respeita ao interesse metodológico, apontamos possíveis implicações para o ensino. Derivar tais implicações pode parecer dispensável, por já ser possível constá-las na prática cotidiana de, pelo menos, alguns professores (caso em que a prática de ensino existe independentemente de um procedimento similar de laboratório). E sendo dispensável, essa derivação pode ser considerada, por conseqüência, desnecessária. Isso, todavia, é um equívoco, pois o ambiente da sala de aula e o ambiente de laboratório, apesar de diferentes, compartilham semelhanças reveladoras de aspectos pelos quais devam ser relacionados. Por falta de treino e/ou por outras razões (falta de orientação, por exemplo), é raro constatar professores enxergarem essas semelhanças para 
além do fato de que fazê-lo possa parecer algo simplesmente óbvio. Também não é freqüente, salvo poucas e louváveis exceções, que analistas do comportamento se preocupem com a pertinência da relação entre sua prática experimental e a prática educacional, quer, a priori, no planejamento e implementação de pesquisas voltadas a problemas em cujo âmbito a relação seja contemplada, quer, a posteriori, no mero exercício dessa relação, pelo menos em termos de discussão dos resultados.

Mesmo ainda incipiente e sob a forma de simples reflexões, a presente análise da derivação de algumas implicações educacionais dos estudos relatados é interessante e um desafio; daí a sua importância. Uma análise mais acurada e ampla, porém, certamente será mais enriquecedora.

\section{Referências}

Álvares, S.M.M. (1996). Discriminações condicionais sem conseqüências diferenciais em crianças: treino por fading e teste precoce de simetria. Dissertação de Mestrado apresentada ao Mestrado em Psicologia: Teoria e Pesquisa do Comportamento da Universidade Federal do Pará.

Álvares, S.M.M., Assis, G.J. A., Esteves. I.P. \& Sampaio, M.E.C. (2001). Discriminações condicionais sem conseqüências diferenciais em crianças: efeitos da história de treino precoce de simetria. Estudos de Psicologia, 6 (1), 7-20.

Assis, G.J.A. \& Galvão, O.F. (1996). Relações condicionais entre palavras conhecidas. Acta Comportamentalia, 4 (1), 5-22.

Assis, G.J.A., Baptista, M.Q.G., Damin, E.T.B. \& Álvares, S.M.M. (1997). Consistency training and equivalence relations without differential consequences. Experimental Analysis of Human Behavior Bulletin, 15 (1), 6-7.

Assis, G.J.A., Baptista, M. Q.G., Kato, O.M. \& Alves, K.R. (2000) Relações de equivalência após treino com pareamento consistente de estímulos sob controle contextual. Psicologia: Teoria e Pesquisa, 16 (2): 125-133.

Baptista, M.Q.G. \& Assis, G.J.A. (1995). Treino por consistência de estímulos sem conseqüências diferenciais. Psicologia: Teoria e Pesquisa, 11 (3), 173-179.

Barros, C.W., Baptista, M.Q.G. \& Assis, G.J.A. (1998). Efeitos da História de Treino na Formação de Classes de Estímulos Equivalentes. Acta Comportamentalia, 6 (2), 111-128.

Bush, K.M., Sidman, M., \& de Rose, T. (1989). Contextual control of emergent equivalence. Journal of the Experimental Analysis of Behavior, 51 (1), 29-45.

Catania, A.C. (1968). Contemporary Research in Operant Behavior. Glenview, Illinois: Scott, Foresman and Company.

Damin, E.T.B., Assis, G.J.A. \& Baptista, M.Q.G. (1998). Efeitos da distribuição de treino e testes na formação de classes de estímulos equivalentes. Psicologia: Teoria e Pesquisa, 14 (1), 41-49.

Gatch, M.B. \& Osborne, J.G. (1989) Transfer of contextual stimulus function via equivalence class development. Journal of the Experimental Analysis of Behavior, 51 (3), 369-378.

Harrison, R.J. \& Green, G. (1990). Development of conditional and equivalence relations without differential consequences.
Journal of the Experimental Analysis of Behavior, 54 (3), 225237.

Lazar, M.R. \& Kotlarchyk, B.J. (1986). Second-order control of sequence-class equivalence in children. Behavioural Processes, 13, 205-215.

Lima, M.P., Assis, G.J.A., Baptista, M.Q.G., \& Sampaio, M.E.C. (1999). Efeitos do arranjo de treino consistente na formação de seqüências. Humanitas, 15 (2)127-142.

Lynch, D.C. \& Green, G. (1991). Development and crossmodal transfer of contextual control of emergent stimulus relations. Journal of the Experimental Analysis of Behavior, 56 (1), 139154.

Reynolds, G.S. (1975). A primer of operant conditioning. Glenview, Illinois: Scott Foresman and Company.

Saunders, R.S., Saunders, K.J., Kirby, K.C., \& Spradlin, J.E. (1988). The merger and development of equivalence classes by unreinforced selection of comparison stimuli. Journal of the Experimental Analysis of Behavior, 50 (2), 145-161.

Schlinger Jr., H.D., Blakely, E., Fillhard, J., \& Poling, A. (1991). Defining Terms in Behavior Analysis: Reinforcer and Discriminative Stimulus. The Analysis of Verbal Behavior, 9, 153-161.

Schoenfeld, W.N. (1995). "Reinforcement" in behavior analysis. The Behavior Analyst, 18 (1), 173-185.

Sidman, M. (1992). Equivalence relations: some basic considerations. Em: S.C. Hayes \& L.J. Hayes (Org.), Understanding verbal relations: The Second and Third International Institute on Verbal Relations (pp. 15-27). Reno, Nevada: Context Press.

Sidman, M. (1994). Equivalence Relations and Behavior: A research story. Boston, MA: Authors Cooperative Publishers.

Sidman, M. \& Tailby, W. (1982). Conditional discriminations versus matching-to-sample: An expansion of the testing paradigm. Journal of the Experimental Analysis of Behavior, 37, 5-22.

Skinner, B.F. (1969). Contingencies of Reinforcement: A Theoretical Analysis. New York, Appleton-Century-Crofts.

Skinner, B.F. (1953/1981). Ciência e comportamento humano. São Paulo: Martins Fontes Editora Ltda. $5^{\mathrm{a}}$ ed.

Sulzer-Azaroff, B., \& Mayer, G.R. (1977). Applying behavioranalysis procedures with children and youth. New York: Holt, Rinehart, and Winston.

Wulfert, E. \& Hayes, S.C. (1988). Transfer of a conditional ordering response through conditional equivalence classes. Journal of the Experimental Analysis of Behavior, 50 (20), 125-144.

Recebido em 08.02.2001

Primeira decisão editorial em 19.05.2002

Aceito em 13.07.2002 